University of Nebraska - Lincoln

DigitalCommons@University of Nebraska - Lincoln

2008

\title{
The Additive Value of Positive Psychological Capital in Predicting Work Attitudes and Behaviors
}

James B. Avey

Central Washington University, aveyj@cwu.edu

Fred Luthans

University of Nebraska - Lincoln, fluthans1@unl.edu

Carolyn M. Youssef

Bellevue University, carolyn.youssef@bellevue.edu

Follow this and additional works at: https://digitalcommons.unl.edu/leadershipfacpub

Part of the Management Sciences and Quantitative Methods Commons

Avey, James B.; Luthans, Fred; and Youssef, Carolyn M., "The Additive Value of Positive Psychological Capital in Predicting Work Attitudes and Behaviors" (2008). Leadership Institute Faculty Publications. 6. https://digitalcommons.unl.edu/leadershipfacpub/6

This Article is brought to you for free and open access by the Leadership Institute at DigitalCommons@University of Nebraska - Lincoln. It has been accepted for inclusion in Leadership Institute Faculty Publications by an authorized administrator of DigitalCommons@University of Nebraska - Lincoln. 
An Article Submitted to

\title{
Journal of Management
}

Manuscript 2421

\section{The Additive Value of Positive Psychological Capital in Predicting Work Attitudes and Behaviors}

\author{
James B. Avey* Fred Luthans ${ }^{\dagger}$ \\ Carolyn M. Youssef ${ }^{\ddagger}$
}

*Central Washington University, aveyj@cwu.edu

${ }^{\dagger}$ University of Nebraska-Lincoln, fluthans@unl.edu

${ }^{\ddagger}$ Bellevue University, carolyn.youssef@bellevue.edu

Copyright (C)2006 by the authors. All rights reserved. No part of this publication may be reproduced, stored in a retrieval system, or transmitted, in any form or by any means, electronic, mechanical, photocopying, recording, or otherwise, without the prior written permission of the publisher, bepress, which has been given certain exclusive rights by the author. 


\title{
The Additive Value of Positive Psychological Capital in Predicting Work Attitudes and Behaviors*
}

\author{
James B. Avey, Fred Luthans, and Carolyn M. Youssef
}

\begin{abstract}
Conventional wisdom over the years and recent research findings have supported the importance of positivity in the workplace. However, to date, empirical analysis has not demonstrated potential added value of recently emerging positive state-like constructs such as psychological capital over the more established positive traits in predicting work attitudes and behaviors. This study of a sample of employees $(\mathrm{N}=336)$ from a broad cross section of organizations and jobs found that their state-like psychological capital is positively related to desired extra-role organizational citizenship behaviors (OCBs) and negatively with undesired organizational cynicism, intentions to quit and counterproductive workplace behaviors. Except for individual OCBs, their psychological capital also predicted unique variance in the same attitudinal and behavioral outcomes beyond their demographics, core self-evaluation, and personality traits, and person-organization fit and person-job fit. The article concludes with implications these findings have for future research and practical application.
\end{abstract}

${ }^{*}$ We would like to thank the editor Tom Wright and three anonymous reviewers for their significant contributions to improving this manuscript. 


\title{
The Additive Value of Positive Psychological Capital in Predicting Work Attitudes and Behaviors
}

\author{
James B. Avey \\ Department of Management \\ Central Washington University \\ 400 E. University Way \\ Ellensburg, WA 98926-7485 \\ Ph/Fax: 5099633381 \\ E-mail: aveyj@cwu.edu \\ Fred Luthans \\ Dept. of Management \\ University of Nebraska \\ Lincoln, NE 68588-0491 \\ $\mathrm{Ph} / \mathrm{Fax} 4024722324$ (5855) \\ Email: fluthans@unl.edu \\ Carolyn M. Youssef \\ College of Business \\ Bellevue University \\ 1000 Galvin Road South \\ Bellevue, NE 68005-3098 \\ $\mathrm{Ph} / \mathrm{Fax} 4025577565$ (5414) \\ Email: carolyn.youssef@bellevue.edu
}

Special Note: We would like to thank the editor Tom Wright and three anonymous reviewers for their outstanding contributions to this manuscript. 


\title{
The Additive Value of Positive Psychological Capital in Predicting Work Attitudes and Behaviors
}

\begin{abstract}
Conventional wisdom over the years and recent research findings have supported the importance of positivity in the workplace. However, to date, empirical analysis has not demonstrated potential added value of recently emerging positive state-like constructs such as psychological capital over the more established positive traits in predicting work attitudes and behaviors. This study of a sample of employees $(\mathrm{N}=336)$ from a broad cross section of organizations and jobs found that their state-like psychological capital is positively related to desired extra-role organizational citizenship behaviors (OCBs) and negatively with undesired organizational cynicism, intentions to quit and counterproductive workplace behaviors. Except for individual OCBs, their psychological capital also predicted unique variance in the same attitudinal and behavioral outcomes beyond their demographics, core self-evaluation, and personality traits, and person-organization fit and person-job fit. The article concludes with implications these findings have for future research and practical application.
\end{abstract}

Keywords: psychological capital; core self-evaluations; organizational citizenship behaviors; organizational cynicism; counterproductive workplace behaviors 


\section{The Additive Value of Positive Psychological Capital in Predicting Work Attitudes and Behaviors}

Positive organizational behavior or POB was first introduced several years ago (see Luthans, 2002a, 2002b; Wright, 2003) as a way to focus in on bringing positive psychology (Seligman \& Csikszentmihalyi, 2000) to the workplace (see Luthans \& Avolio, 2009 and Luthans \& Youssef, 2007 that respectively traces the development and meaning of POB and provides an overall comprehensive literature review of POB). It has been defined as "the study and application of positively oriented human resource strengths and psychological capacities that can be measured, developed, and effectively managed for performance improvement" (Luthans, 2002b, p. 59; also see Wright, 2003). Using positivity, theoretical foundation, valid measurement, state-like developmental potential, and performance impact as their criteria of inclusion, Luthans and colleagues identified from the positive psychology literature efficacy, hope, resilience, and optimism as being especially (but not exclusively) relevant to POB (see Luthans, 2002a; Luthans \& Youssef, 2007; Luthans, Youssef \& Avolio, 2007. In addition, see Stajkovic, 2006, which also focuses on these four constructs in a core-confidence theoretical model).

Although each of these psychological resources has differing theoretical perspectives and definitions, efficacy is defined here as “one's conviction (or confidence) about his or her abilities to mobilize the motivation, cognitive resources, and courses of action needed to successfully execute a specific task within a given context" (Stajkovic \& Luthans, 1998b, p. 66). Hope is defined as "a positive motivational state that is based on an interactively derived sense of successful (1) agency (goal-directed energy) and (2) pathways (planning to meet goals)" (Snyder, Irving, and Anderson, 1991, p. 287). Optimism is both a positivity-oriented future expectation (Carver \& Scheier, 2002) and an attributional style that interprets specific positive 
events through personal, permanent and pervasive causes, and negative events through external, temporary and situation-specific ones (Seligman, 1998). Resiliency is "the capacity to rebound or bounce back from adversity, conflict, failure, or even positive events, progress, and increased responsibility" (Luthans, 2002a, p. 702). Taken together, these four have been theoretically developed and empirically tested as a state-like positive core construct termed psychological capital (or simply PsyCap) (Luthans, Avolio, Avey \& Norman, 2007; Luthans, Youssef \& Avolio, 2007). Specifically, psychological capital is defined here as “an individual's positive psychological state of development that is characterized by: (1) having confidence (self efficacy) to take on and put in the necessary effort to succeed at challenging tasks; (2) making a positive attribution (optimism) about succeeding now and in the future; (3) persevering toward goals and, when necessary, redirecting paths to goals (hope) in order to succeed; and (4) when beset by problems and adversity, sustaining and bouncing back and even beyond (resilience) to attain success" (Luthans, Youssef, Avolio, 2007, p. 3).

Following the lead of positive psychology, considerable attention has recently been devoted to positive organizational behavior in general (e.g., see the review article in the Journal of Management, Luthans \& Youssef, 2007 and two special issues in Journal of Organizational Behavior edited by Bakker \& Schaufeli, 2008 and Wright \& Quick, 2009) and psychological capital in particular (e.g., see Luthans, Avolio et al., 2007; Luthans, Youssef \& Avolio, 2007). Even though the field of organizational behavior over the years has probably given relatively more attention to positively-oriented positive constructs than has psychology, there is this recent renewed focus on positive organizational behavior (Luthans \& Avolio, 2009). However, at this stage of the development of POB, empirical analysis is now needed to assess whether these recently emerging positive state-like constructs such as psychological capital adds value to the already established positive trait-like constructs such as self-evaluation, Big Five personality 
dimensions, and person-job/organization fit in predicting important, yet to date untested, work behaviors and attitudes such as desired organizational citizenship and undesired cynicism, intentions to quit and counterproductive actions. After first providing the overarching and specific theoretical foundation for psychological capital, study hypotheses are derived, and the methods and results of analyzing the relationship between psychological capital and these work behaviors and attitudes are presented and its value-added contribution assessed.

\section{Overarching Theoretical Framework}

Positive psychology claims neither discovery of nor monopoly over positivity - only a shift and reemphasis that may necessitate a different lens or perspective (Seligman \& Csikszentmihalyi, 2000). Similarly, Luthans and Avolio (2009) recently noted that positive organizational behavior (or we will refer to as POB) is sometimes accused of being old wine in a new bottle. They counter such criticism by using another metaphor. Reacting to the "old wine" metaphor, they assert that POB is at minimum being served in a "new restaurant." This "new restaurant" metaphor refers to the context in which positivity research is now taking place, in terms of the changing environment facing today's organizations (e.g., globalization, advanced technology), the relative novelty of some of the constructs to the field of organizational behavior (e.g., hope, optimism, resiliency), and the changing expectations of employers (e.g., organizational citizenship behaviors vs. just in-role performance) and employees (e.g., lifelong development and alternative career paths vs. employment based on seniority security and a paycheck).

This new context in which positivity research (and practice) currently takes place may not readily lend itself to conventional wisdom nor traditional conceptual models. While POB includes the scientific process for its foundation and inclusion criteria, the outlook of positive conceptual frameworks, although deeply grounded in the wealth of existing theories and 
empirical findings to-date, may be relatively unique. For example, a primary emphasis on organizational efficiency goals (e.g., financial and subjectively rated employee performance) may need to be integrated with meeting the needs of the organization's other important assets, namely its leaders and associates, for jobs and careers that provide identity, meaning and fulfillment, and organizations that are caring, compassionate, and virtuous (e.g., Youssef \& Luthans, 2008; also see: Wright \& Goodstein, 2007; Wright \& Huang, 2008). While important and significant in their own right, many human-oriented organizational initiatives are not recognized nor given credibility because of the inherent difficulties in justifying them in quantifiable return-on-investment terms. Psychological capital (or we will refer to as PsyCap) aligns the pursuit of positivity, flourishing and human fulfillment at work, with the bottom-line oriented measures required for adequate resource allocation within the realities of today's competitive environment. This need for a new perspective has recently stimulated the development of an integrated conceptual model (see Youssef \& Luthans, 2009) and can be used as a theoretical framework for the current study characterized by balanced and multi-level perspectives and a broad set of outcomes.

\section{A Balanced Perspective}

Although more positively-oriented than mainstream and especially clinical psychology, organizational behavior research tends to focus on one side of the (positive-to-negative) continuum, often to the exclusion of the other (e.g., stress not eustress or satisfaction not dissatisfaction). Specialization has led many researchers to emphasize their areas of expertise (which may focus on positive, neutral or negative constructs), with limited, if any, attention given to the other side. If positive organizational behavior does not adopt a balanced perspective from its early beginnings, it can also easily take a similarly myopic perspective. In other words, "positive" organizational behavior may be short-sighted and hampered if it adopts an advocacy 
perspective and an exclusive bias toward positive constructs. Instead, Luthans and Avolio (2009) argue that integration and a positive inquiry mode should be the aim of POB. This is especially true for constructs and contexts where the positive and the negative may represent qualitatively different, but at the same time potentially co-existing phenomena, rather than opposite, mutually exclusive ends of a single continuum (e.g., optimism vs. pessimism, see Peterson \& Chang, 2002; also see Hackman, 2009; Lazarus, 2003).

\section{A Multi-Level Perspective}

Since positive organizational behavior draws some of its uniqueness from the new realities of today's workplace (i.e., the "new restaurant"), it is unlikely that an isolated emphasis on the individual level of analysis without considering contextual factors will yield meaningful findings. In fact, one of the major criticisms of the positivity literature is its preoccupation with individual level variables, while it is the cross-level interactions among individuals, groups and the organizational and cultural context within which they relate that shape most of the outcomes (Hackman, in press). While we believe that the predominance of individual-level, "feel good" ideas tends to come from the popular self-help literature, we assert the importance of considering multiple levels of analysis in organizational behavior research in general, and positive organizational behavior in particular.

Early on in the conceptualization of positive organizational behavior, Luthans and Avolio's (2003) authentic leadership model viewed the interaction of individual life experiences and a positive organizational context as critical antecedents for the development of leaders' PsyCap. Similarly, Youssef and Luthans' (2009) recent integrative model also takes into consideration organizational-level factors such as organizational strategy, structure, culture, and recent changes, as well as individual-level antecedents such as personality traits and previous life experiences, as antecedents for PsyCap. In this integrative model, the interaction between the 
individual and the organizational context is operationalized through the person-organization and person-job fit. Moreover, not only are individual-level outcomes of positivity considered, but also short-term organizational efficiency (e.g., ROI, stock value) and long-term organizational effectiveness (e.g., long term growth, increased market share, innovation, social responsibility).

\section{A Broader Set of Outcomes}

Besides balance and multi-level perspectives, Youssef and Luthans' (2008a) model also proposes a more holistic perspective that necessitates the integration of work-related attitudes, behavioral intentions and actual behaviors. For example, in the context of ethical decision making, Jones (1991) supports the need for integrating attitudes and intentions in predicting positive ethical behaviors. Parallels can be drawn between this ethical process and the impact of psychological capital. One such parallel is that the impact of PsyCap may go beyond enhanced "in-role" performance, to also include positive attitudes, intentions and "contextual" behaviors that can ultimately lead to desirable outcomes such as ethical performance. In line with the need for this more holistic perspective is the impact that positivity may have on various employee attitudinal and behavioral outcomes in today's workplace. Importantly, this integrative model proposes that there is a need to examine the impact of PsyCap on both desirable and undesirable behaviors and attitudes.

As with any domain, we acknowledge that it would be challenging to expect every study that investigates the role of positivity in the workplace to comprehensively incorporate the full breadth of individual and contextual factors, as well as the attitudinal, intentional, behavioral and performance outcomes related to positivity. However, given the nature of positivity in the workplace and the need for an integrated framework and a holistic perspective, we suggest that research is needed that at least analyzes a representative sample of these different categories of variables. We also suggest that taking positivity out of its broader context of antecedents, 
covariates, and outcomes without accounting (or at least controlling) for a critical mass of these variables may be unrealistic.

The purpose of this study is to begin to test an integrated conceptual model of positive organizational behavior (Youssef \& Luthans, 2009) and also heed Hackman's (2009) concerns about positivity research's preoccupation with only positive, individual-level variables that may be of limited direct economic value to organizations. We now turn our focus to the more specific theoretical and research grounding for the recently emerging core construct of psychological capital.

\section{Psychological Capital (PsyCap)}

PsyCap attempts to integrate and advance the positive approach to organizational behavior in several ways. In addition to the POB inclusion criteria of being positive, theoretically-based, measurable, developmental, and performance-related, PsyCap as defined in the introductory comments is conceptualized, measured and developed in terms of a state-like positive core construct, to which each of the individual resources of efficacy, hope, optimism, and resiliency synergistically contributes. Several foundational characteristics of this PsyCap core construct require added emphasis before the study hypotheses are derived.

\section{PsyCap as a State-Like Construct}

In terms of developmental potential, it is important to note that PsyCap, as well as each of its constituent resources or capacities, considered "state-like" as found in the positive psychological literature (e.g., for efficacy see Bandura, 1997; hope- Snyder, 2002; resilienceMasten \& Reed, 2002; optimism- Carver \& Scheier, 2002 and Seligman, 1998), rather than just a fixed trait. Although positive traits and states do share some common characteristics, both conceptually (e.g., positivity) and empirically (e.g., positive correlations, common correlates and related outcomes), recent theory-building and empirical research also supports their 
distinctiveness and discriminant validity. For example, Luthans and Youssef (2007) make the case for a trait-state continuum that spans from: (a) pure positive traits: one extreme on the continuum characterized by stability over time and across situations, including traits that are believed to be "hardwired" such as intelligence or hereditary characteristics; (b) trait-like constructs: closer to the trait end of the continuum, and refer to relatively stable psychological characteristics such as conscientiousness, extraversion and core self-evaluations; (c) state-like psychological resources: closer to the opposite (state) end of the continuum, and include PsyCap and its constituents of efficacy, hope, optimism, and resiliency (the focus of this study), which tend to be malleable and thus open to development and are particularly relevant to the workplace; and finally (d) positive states: the other extreme of the continuum, including momentary and highly variable states such as moods and emotions (for related discussion, see also Luthans, Avolio, et al., 2007; Luthans, Youssef \& Avolio, 2007; Youssef \& Luthans, 2007).

Several cognitive, affective and social mechanisms warrant the conceptual distinction between PsyCap and other related organizational behavior constructs that may share some, but not all of PsyCap's characteristics, and thus occupy varying locations on the trait-state continuum described above. For example, Hannah and Luthans' (2008) recent cognitive affective processing system provides a theoretical framework that can help understand some of these mechanisms. In this model, PsyCap is specifically proposed to result from dynamic processes that activate the adaptive encoding of cognitive categories, expectancies, goals, values, affects and self-regulatory plans. These processes are selectively activated and context specific. On the other hand, traits and trait-like characteristics are more global in nature, exhibited based on the chronic activation of certain sets of cognitive affective processing units, and represent habitual or programmed responses that can be primed through exposure to pre-determined stimuli. 
For example, while some people may exhibit generalized efficacy (a trait-like, not statelike construct as conceptualized by Bandura, 1997), which may cause them to come across as confident individuals over time and across situations, others may seem to lack this confidence. On the other hand, self-efficacy (a state-like capacity as conceptualized by Bandura, 1997 and a key component of PsyCap) is more domain-specific and can be developed for a specific set of tasks (e.g., a job) through mastery experiences, modeling, social persuasion, and physiological and psychological arousal (Bandura, 1997). These developmental components as conceptualized by PsyCap can create positive expectancies, trigger the creation of goals with an approachorientation (rather than avoidance or complacency), and motivate self-regulatory mechanisms that increase the probability of perseverance and success in a particular situation.

Similarly, each of PsyCap's other identified capacities possesses this developmental and contextualized nature (e.g., hope requires effectively setting specific goals and the determination and pathways to achieve them, optimism requires active causal attributions for specific events, and resiliency requires successful bouncing back from specific setbacks). PsyCap's foundation also draws from social cognitive theory (Bandura, 1997), which establishes reciprocal interactions between the person, the environment, and past behavior. This theory provides added support for the distinction between general personality traits or trait-like characteristics such as found in the Big Five dimensions and the more contextualized and malleable PsyCap construct.

On the other hand, state-like PsyCap is not as transient and momentary as the more extreme states such as moods or emotions. For example, unlike emotions, whose at-the-moment meaning and intensity may be constructed through subjectively negotiated appraisal processes for more effective coping (Lazarus, 2003), PsyCap capacities share a cognitive agentic component that needs to reach and maintain a certain threshold of intensity and endurance in order to result in measurable success and tangible goal achievement. Although positive emotions 
may exist as a by-product of the accomplishment of more concrete goals and objectives, the "performance impact" inclusion criterion of POB and PsyCap goes far beyond "emotion focused coping" (a more benign reappraisal of a harmful or threatening situation, Lazarus, 2003, p.95), and even "problem focused coping" (a more action-oriented initiative to change the situation, Lazarus, 2003, p. 95).

Empirically, the distinction between traits and states has been supported by very high test-retest correlations for recognized traits such as personality (e.g., Conley, 1984) and highly significant but still relatively lower correlations for state-like constructs such as PsyCap (e.g., see Luthans, Avolio et al., 2007). Relatively short training interventions have also been successfully implemented to develop PsyCap (Luthans, Avey, Avolio, Norman, \& Combs, 2006; Luthans, Avey, \& Patera, 2008). Based on such empirical findings and others, Wright (1997) emphasized the importance of time as a main effect variable in organizational behavior research, and proposed stability over six months as an operationalization of the temporal distinction between traits and states.

\section{PsyCap as a Core Construct}

The integration of hope, efficacy, resilience and optimism represents the core construct of psychological capital or PsyCap. This PsyCap can be considered a multi-dimensional construct identified by these four positive psychological resources. To address theoretical rationale and construct validity of PsyCap, two important aspects need to be especially emphasized: (a) the convergent and discriminant validity between PsyCap and other positive constructs and (b) the convergent and discriminant validity between PsyCap's constituent capacities. Above we have already addressed parts of the first point by clarifying some of the subtle but important differences between PsyCap as a "state-like" construct, and other similar capacities that lie on different points of a trait-state continuum. Elsewhere (e.g., see Luthans, Youssef \& Avolio, 
2007), a wide variety of positive psychological constructs such as wisdom, courage and emotional intelligence have been assessed for their fit with the identified POB inclusion criteria. However, to date efficacy, hope, optimism, and resilience continue to offer the best-fitting resource components for PsyCap (see Luthans, Youssef \& Avolio, 2007). For example, many constructs from the positivity literature may be of terminal value (valuable in their own right, e.g., compassion), but not necessarily due to their measurable performance impact. Others may be trait-like (or at least closer to the trait end of the continuum), and thus only lending themselves to lifelong development, rather than to the short developmental interventions commonly utilized in the workplace. Still others may be intuitively appealing, but lack theoretical support or valid measurement (e.g., much of the popular personal development literature).

By the same token, PsyCap does converge with several more established and relevant positive constructs. For example, a similar, but trait-like, multi-dimensional construct is core self-evaluations (CSEs), which include self-esteem, generalized self efficacy, locus of control, and emotional stability. Core self-evaluations are fundamental, subconscious self-appraisals that generally affect individuals' evaluations of themselves, the world, and others, and have been found to globally influence their appraisals and behaviors across situations (Judge \& Bono, 2001). Conceptual similarities appear evident between the components of PsyCap and CSEs (e.g., general and specific efficacy, locus of control and an optimistic explanatory style, emotional stability and resilience). Similar to PsyCap, research supports self-evaluations as a core construct to which the four trait-like characteristics contribute (Judge \& Bono, 2001). To date, previous empirical findings do support convergent $(\mathrm{r}=.6)$ and discriminant validity between PsyCap and CSEs (Luthans, Avolio et al., 2007). 
Concerning the second point on PsyCap being a multi-dimensional core construct, the convergent and discriminant validity between PsyCap's four component capacities has also been supported by previous research (Luthans, Avolio et al., 2007). In other words, despite the apparent conceptual similarities and overlap between hope, resiliency, optimism, and efficacy, each of these positive constructs has conceptually and empirically been analyzed and demonstrated to have construct validity. For example, conceptually efficacy and hope share the components of internalized motivation and energy, or the positive expectation of success for the reason of belief in one's individual abilities. Highly efficacious and hopeful employees both set challenging goals for themselves and self-select into challenging assignments with motivation and tenacious effort toward success. However, the pathways component, which constitutes "waypower" or the ability to generate alternative pathways toward specific goals, is unique to hope. A hopeful individual's propensity to develop alternative, contingency, or back-up plans to accomplishing the same goal constitutes what Snyder (1994, p. 247) refers to as "fallibility insurance", where people will remain hopeful in goal accomplishment as there will always be an alternative route to pursue. Hopeful individuals are never out of options, they sustain hope of eventual success. Thus, hope can provide added substance, namely more pathways to consider, for the internalized motivation, energy and perseverance of an efficacious person.

As another example, efficacy, hope and optimism all share positive expectancies about the future. However, optimism may be more general in nature, and may constitute a global positive expectation of success, while hope and self-efficacy tend to be more specific to a particular goal or domain. Thus, optimism about the future can be capitalized upon in domains where efficacy or hope have not been previously built. Furthermore, unlike efficacy and hope, in which positive expectancies are internalized, and attributed to one's effort and motivation, an optimistic explanatory style may use other people or situational factors as referents, especially 
when externalizing negative events. Similarly, resiliency is not limited to an internalized, agentic perspective, but expands the circle of influence to include social support and other organizational-level resources and buffering mechanisms. This perspective goes beyond the modeling and vicarious learning contribution of others in building efficacy, to incorporate other resources from the environmental context that may be drawn upon when internal resources are lacking, depleted, or otherwise inadequate, or to buffer the influence of risk factors that may be beyond the individual's capacity to handle. Examples of buffering mechanisms from the organizational context include organizational sensemaking, organizational learning, and collective schemata/ mental models development.

In addition, while efficacy, hope and optimism tend to be proactive in nature, resilience is most often expressed in a reactive mode, as a response to a setback. However, resilience shares several interesting characteristics with efficacy, hope and optimism. Both efficacy and resilience have an underlying perseverance component that motivates endurance in the face of obstacles. While the context of the setbacks may be different (characterized by proactive pursuit of specific self-set goals in the context of efficacy, but reactively in resilience), both capacities motivate persistence and a "keeping at it" outlook.

Hope and resilience also share a process-orientation, in which the mechanisms that link the person to the desired outcomes are most critical for success. According to Masten and Reed (2002), resilience is comprised of adaptational processes, which are mechanisms developed by highly resilient individuals to effectively employ their available assets (e.g., cognitive, affective, social, financial, and other positive characteristics, skills and resources) to mitigate the impact of their risk factors (e.g., weaknesses, deficiencies, and other negative factors that have the potential to amplify setbacks). Resilience is manifested when appropriate adaptational processes are utilized to draw upon the right assets to withstand or recover from setbacks fueled by risk 
factors. In the same way that the process of generating alternative pathways is integral for the sustenance of hope, the effectiveness of one's adaptational processes may be more critical for resilience than the simple additive sum of existing assets and risk factors.

As indicated in the introductory definition and noted by Luthans, Avolio et al. (2007, p. 550), the underlying common agentic capacity running through the four components of PsyCap is the "positive appraisal of circumstances and probability for success based on motivated effort and perseverance." In other words, in addition to meeting the POB inclusion criteria, the common denominator for the convergence of PsyCap's four constituent psychological capacities is represented by a core factor of internalized agency, motivation, perseverance, and success expectancies. On the other hand, the extent and nature of environmental influences, and the adaptational mechanisms and goal achievement processes, vary across the four capacities, making each capacity's contribution unique to the multidimensionality of PsyCap.

Other explanatory frameworks for integrating these four positive psychological resources are described by Hobfoll (2002) in his review of various psychological resource theories and Stajkovic (2006) who theoretically links these four constructs into a core-confidence model. Law and colleagues (1998) also propose that a second order factor comprised of four indicators such as PsyCap is best considered as comprised of the shared variance between each component. This second order, core factor of PsyCap consisting of the shared variance of hope, efficacy, optimism, and resilience has recently been empirically demonstrated (Luthans, Avolio et al., 2007). Importantly, this previous research using a competing measurement models analysis found PsyCap was best measured as a second order factor, whereby each of the four dimensions loads onto the overall core factor (PsyCap) and usefulness analysis indicated PsyCap was more consistently related to both performance and satisfaction than each of the individual components by themselves (Luthans, Avolio et al., 2007). 
Considerable empirical findings demonstrate both convergent and discriminant validity of the four positive constructs that make up PsyCap (e.g., see Bryant \& Cvengros, 2004; Carifio \& Rhodes, 2002; Magaletta \& Oliver, 1999), including when analyzed with employee samples (Luthans, Avolio et al., 2007). Overall, this conceptual and empirical analysis provides considerable support for PsyCap as a core construct made up of the four identified positive resources.

\section{Psychological Capital and Workplace Outcomes}

As indicated, the overarching theoretical framework for this study makes the case that examining in-role performance should be supplemented with a balanced combination of desirable and undesirable attitudinal and behavioral outcomes (see Youssef \& Luthans, 2009). Since the relationships between PsyCap and desirable attitudinal outcomes such as job satisfaction, work happiness, and organizational commitment have already been empirically supported (Luthans, Avolio et al., 2007; Luthans, Norman et al., 2008), this study expands the boundaries of positivity research by investigating the negative attitude of cynicism relevant to today's workplace (for the role cynicism may play in positive organizational change, see Avey, Wernsing \& Luthans, 2008).

Organizational participants with higher PsyCap are likely to experience lower levels of cynicism, for several reasons. First, as discussed earlier, higher levels of PsyCap capacities such as hope and optimism have been shown to trigger positive emotions (Snyder, Harris et al., 1991) as a byproduct of positive appraisals and increased probabilities of success and goal accomplishment. Second, PsyCap's agentic thinking has a motivating impact that can enhance internalization, determination, and pathways thinking, which contradict with the "giving up" and despair associated with cynicism. Third, hopeful people also experience fewer negative emotions, even when faced with obstacles, primarily due to their waypower (Snyder, Ilardi, 
Michael, \& Cheavens, 2000). Together, increased positive emotions, motivated agentic cognitions, and decreased negative emotions can help activate more positive cognitive affective processing system units (e.g., positive expectancies, approach rather than avoidance goals, see Hannah \& Luthans, 2008) that can help reduce cynicism. On the other hand, Snyder, Harris and colleagues (1991) argue that when hope is low, "analysis of insufficient agency and pathways in a given goal setting should lead to perceptions of relatively low probability of goal attainment, a focus on failure rather than success, a sense of ambivalence, and a relatively negative emotional state during goal related activities," i.e., cynicism. Thus, we hypothesize the following:

Hypothesis 1: PsyCap will be negatively related to organizational cynicism.

Individuals who are higher in PsyCap are likely to have lower turnover intentions for several reasons. Their higher levels of optimism regarding the future and confidence in their ability to succeed in their current job will motivate them to take charge of their own destinies (Seligman, 1998), self-select into challenging endeavors (Bandura, 1997), engage the necessary efforts and resources, and persevere in the face of obstacles (Stajkovic \& Luthans, 1998a), rather than become "quitters." In addition, due to higher levels of resilience, even when they experience negative events in the workplace, high PsyCap individuals are more likely to positively adapt and bounce back from those events, preventing the escalation and development of intentions to quit. Finally, those higher in the hope capacity are more able to derive multiple pathways to be successful in the present job, further reducing the perceived need to leave the organization.

Although for some, a viable pathway might be changing jobs (turnover), high hope tends to motivate approach goals, in which a person chooses to actively pursue positive outcomes, rather than avoidance goals, in which negative or threatening situations are simply shunned. Moreover, turnover intentions have been conceptualized as a function of job satisfaction and 
future expectancies in current versus alternative jobs, which in turn are based on economic and labor market conditions (Mobley, Griffeth, Hand, \& Meglino, 1979). Given the support to-date for a positive relationship between PsyCap and job satisfaction (Luthans, Avolio, et al., 2007), it follows that high PsyCap would be a negative, rather than a positive predictor of turnover intentions, especially given the negativity of the recent economic environment. Based on the above, the following is hypothesized for this study.

\section{Hypothesis 2: PsyCap will be negatively related to intentions to quit the organization.}

Not only is PsyCap expected to be related to work attitudes and behavioral intentions, but also to extra-role behaviors in organizations. As cited earlier, there is emerging both theory and empirical findings supporting the positive relationships between PsyCap and desirable behaviors leading to performance and negative relationships with undesirable behaviors such as absenteeism. This study expands the boundaries of the existing POB literature by concurrently investigating both desirable and undesirable "contextual performance" indicators, operationalized as organizational citizenship behaviors (OCBs) and counterproductive work behaviors (CWBs)

OCBs are those desirable behaviors that are not prescribed by or enforced in the existing job role but may be practiced at the option of the individual employee. Lee and Allen (2002) note that OCBs can be separated into two distinct referents. First, individual oriented OCBs are those that use others as the referent. This may include staying late on the job to help a co-worker or supporting a newcomer to the group. The second referent for OCBs is the organization. Organizationally oriented OCBs are those behaviors that support the organization. This may include attending organizational events that are not required or doing volunteer work in the community to indicate support from the employer. The extra-role, "above-and-beyond" nature of OCBs is particularly relevant to a broader, holistic, integrated outcome from positivity. This is 
especially true given the narrowness and short-term orientation of most performance appraisal and reward systems in today's organizations.

Opposing the positive OCBs are the negatively-oriented counterproductive work behaviors or CWBs. Bennett and Robinson (2000, p. 556) define these as "voluntary behavior of organizational members that violates significant organizational norms, and in doing so, threatens the well-being of the organization and/or its members." Similar to OCBs, CWBs can be expressed in the form of interpersonally deviant behaviors such as harassment of, violence against, gossip about, or theft from a coworker. They can also take the form of organizationally deviant behaviors such as intentionally working at a slower rate, sabotaging company property, or sharing confidential company information (Robinson \& Bennett, 1995). However, interpersonal and organizational deviance are highly correlated and the distinction between them has been recently critiqued (Berry, Ones \& Sackett, 2007). Recent empirical studies indicate that momentary negative emotions (discussed earlier as a component of cynicism) are positively related, while job satisfaction is negatively related, to CWBs (Judge, Scott, \& Ilies, 2006).

Despite the significant (negative) correlation between OCBs and CWBs, recent empirical findings support OCBs and CWBs as two distinct constructs, with different correlates and consequences, rather than opposite ends of a single continuum (Sackett, Berry, Wiemann, \& Laczo, 2006), making them particularly relevant for the balanced perspective of outcomes proposed for this study. Moreover, despite some overlap, the behavioral expressions of OCBs and CWBs are conceptually distinct. For example, while refusing to help a coworker constitutes a counterproductive behavior, an OCB may go beyond just extending the help that the coworker asks for, to also doing so without expecting any material rewards, recognition, or reciprocation, and even encouraging the coworker to ask for help again in the future. 
Individuals higher in PsyCap would seem to be more likely to engage in OCBs than those with lower PsyCap for several reasons. In general, employees who are more positive would seem to exhibit more OCBs than employees who tend to be negative. Several relevant mechanisms could provide support for the conceptualization of this relationship. For example, Fredrickson's (2003) model supports a broadening contribution of positive emotions, in which people experiencing those emotions utilize broader thought-action repertoires, increasing the potential for proactive extra-role behaviors such as sharing creative ideas or making suggestions for improvement. There are also recent organizationally-based studies that have used this broadenand-build model to test the role of positively-oriented psychological well-being as a moderator of both the relationship between job satisfaction-job performance (Wright, Cropanzano \& Bonett, 2007) and job satisfaction-employee turnover (Wright \& Bonett, 2007). Besides this research support for the role of positive well-being for both in-role performance and turnover behaviors, the specific characteristics of the positive psychological resources that constitute PsyCap, namely hope, resilience, optimism and efficacy, we propose may to lead to more frequent engagement in extra-role (i.e., broaden-and-build) OCBs.

To understand a negative relationship between PsyCap and CWBs, an examination of the source of CWBs seems important. Specifically, Fox and Spector (1999) advance the argument that workplace constraints, acting as stressors, are the primary cause of CWBs. First, employees are exposed to stressors (e.g., having to rely on incompetent colleagues in order to personally succeed) and then respond with CWBs (e.g., failing to help a co-worker or sabotage). An important mechanism in the relationship may be that individuals higher in PsyCap are less susceptible to the negative influence of stressors, and thus exhibit fewer CWBs. Specifically, those high in PsyCap may be more resilient to stressful events, stressors and setbacks (Masten \& Reed, 2002) and do not experience the negative repercussions as strongly. In addition, when 
exposed to stressors, instead of responding with CWBs, individuals high in PsyCap would be expected to remain optimistic that the situation will improve (Carver \& Scheier, 2002), generate plans and pathways to change the situation for the better (Snyder et al., 2000), and feel efficacious in their own abilities to persevere in the situation and continue being successful despite the adversity (Bandura, 1997). Thus, instead of responding to stressors with CWBs, those higher in PsyCap respond by positively adapting to the situation and becoming successful. Based on the above, the final two study hypotheses are as follows:

Hypothesis 3: PsyCap will be positively related to organizational citizenship behaviors. Hypothesis 4: PsyCap will be negatively related to counterproductive workplace behaviors.

\section{Control Variables}

In this study, we offer that given the state-like, developable nature of PsyCap (Luthans, Avey, et al., 2006; Luthans, Avey, \& Patera, 2008; Luthans, Avolio et al., 2007), the value-added contribution of PsyCap to workplace outcomes can be better understood and assessed when controlling for dispositional, stable trait-like characteristics. Based on the overarching conceptual framework discussed earlier, in addition to traditional demographic control variables, we have selected the Big Five personality traits of conscientiousness and extroversion, as well as core self-evaluation (CSE) traits, as control variables. These widely recognized positive traits have been shown to have significant impact on performance (e.g., Barrick \& Mount, 1991; Judge \& Bono, 2001). It follows that they should be accounted for when attempting to study the added value of PsyCap, especially given the conceptual similarities between them. For example, conscientiousness, which has one of the strongest reported relationships with work performance across various jobs and industries, includes responsibility, self-discipline, hard work and persistence. These trait-like characteristics may overlap with PsyCap in terms of the more state- 
like resources of efficacy's motivated hard work, hope's willpower, optimism's internalized attributions, or resiliency's perseverance. Similarly, extroverts may be more able to reach out to others, building more of the social assets that can contribute to their resiliency and tend to use others when making attributions in their optimistic explanatory style.

Despite the primarily cognitive nature of PsyCap, it is not devoid of emotions, which tend to be a by-product of positive cognitive processing of the personal and situational factors at hand (see earlier discussion and Hannah \& Luthans, 2008). Thus, controlling for the CSE trait of emotional stability (or neuroticism) would factor out the trait-like affective component that may confound the contribution of PsyCap, by accounting for an individual's disposition toward being calm, secure, or generally unworried, instead of having built efficacy or created effective pathways for hope. Recent meta-analytic findings also support emotional stability as the strongest of the Big Five personality traits in predicting turnover intentions, followed by conscientiousness and extraversion (Zimmerman, 2008). Since turnover intentions are among the outcome variables investigated this study, it is important to isolate the contribution of PsyCap over and above those three traits.

Besides controlling for established positive traits, in line with the overarching conceptual framework driving this study, we also recognize the critical role that the organizational context may play in enhancing or hindering the development of PsyCap, as well as in facilitating or hindering its impact on employee outcomes. We posit that the role of the organizational context is often inseparable when attempting to understand workplace human variables in general, and PsyCap development and management in particular. Hannah and Luthans (2008) also conceptualized PsyCap in terms of the in-situ dynamic activation of cognitive affective processing system units and based the fit between the person's self-construct and perceived situational demands. Drawing from Youssef and Luthans' (2009) conceptual model, this study 
specifically examines the role of person-organization (PO) fit and person-job (PJ) fit due to their integration of individual and organizational variables, as well as the potential reciprocal relationships between those variables. PO fit can be defined as the degree of congruence or complementary relationship between individuals and their organizations in terms of goals, needs, supplies (capabilities, resources), values, norms or behaviors (Chatman, 1989; Kristof, 1996).

PJ fit refers to the compatibility or match between a person's traits, needs, knowledge, skills and abilities, and the demands of the job (Caldwell \& O'Reilly, 1990). Person-situation fit in general has established relationships with desirable performance and attitudinal outcomes. For example, the Gallup studies support that people who are placed in jobs that match their talents, and who work for strengths-based organizations that develop them along their areas of strength, tend to experience higher engagement and well being, resulting in higher performance (Harter, Schmidt, \& Hayes, 2002). Since PO and PJ fit can contribute to performance and attitudinal outcomes in their own right (e.g., Kristof-Brown, Zimmerman \& Johnson, 2005), as well as indirectly through providing a supportive environment for the development of PsyCap that can in turn enhance those desirable outcomes, it is important to account for the contribution of PO and PJ fit in order to realistically assess the added contribution of PsyCap.

\section{Methods}

This study utilized a sample of 336 employees from a wide cross section of organizations and jobs who agreed to participate in a large Midwestern university sponsored research project on leadership and motivation. Sixty percent of the participants were in non-management positions and approximately 38 percent were in positions that included supervision (from first level manager to CEO or owner). Participants had an average age of 32 years and average job tenure of 12 years. Approximately 88 percent were Caucasian with 3 percent Asian, 1 percent 
African-American and a very small percentage were Hispanic and Native American. One third reported having obtained an undergraduate degree.

\section{Measures}

To assess psychological capital, the recently developed ( see Luthans, Youssef \& Avolio, 2007) and psychometrically analyzed (see Luthans, Avolio et al.,2007) 24 item PsyCap

Questionnaire (PCQ)was used. This instrument has adapted 6 items each from published hope (Snyder et al., 1996), efficacy (Parker, 1998), resilience ( Wagnild \& Young, 1993) and optimism ( Scheier \& Carver, 1985) scales. The entire PCQ can be seen in Luthans, Youssef and Avolio ( 2007, pp. 237-238) and free permission can be obtained for research purposes at www.mindgarden.com. Sample items include: "I feel confident helping to set targets/goals in my work area" (self-efficacy); "Right now I see myself as being pretty successful at work" (hope agency); "If I should find myself in a jam at work, I could think of many ways to get out of it" (hope pathways); "When I have a setback at work, I have trouble recovering from it, moving on" (reverse scored resiliency); and "I always look on the bright side of things regarding my job" (optimism).

In this study, each subscale $($ Efficacy $=.92$. Hope $=87$, Resilience $=.83$, Optimism $=$ .78) and the overall PCQ (.95) demonstrated adequate internal reliability. In addition to internal reliability, using the MPlus software, a confirmatory factor analysis was conducted using maximum likelihood techniques and replicated the second order factor structure previously reported by Luthans, Avolio and colleagues (2007). Specifically, this analysis conducted confirmatory factor analytic model comparisons to determine the statistically best performing measurement model. To this end, each of the four components were modeled: (1) as individual factors; (2) as sub factors of the PsyCap latent factor; and (3) with all 24 items loading on to a single latent factor. Using $\chi^{2}$ difference tests, this analysis found that the hypothesized model 
(model 2), where the dimensions were distinct and represented as indicators of a core underlying factor (PsyCap), emerged as the superior model in terms of model fit (see Luthans, Avolio et al., 2007, p. 559). In terms of the present CFA, Hu and Bentler (1999) describe the combinatorial rule that if the SRMR meets the cutoff criteria and the CFI or RMSEA meets the criteria then there is satisfactory model fit. They note the recommended cutoffs are a CFI $\leq .95, \mathrm{RMSEA} \leq$ .08 and $\mathrm{SRMR} \leq .06$. Accordingly, this CFA revealed adequate factor analytic fit (SRMR $=.05$, RMSEA $=.05, \mathrm{CFI}=.96$.$) ). Item loadings for the 24$ items ranged from .67 to .95 and there were no significant cross loaded items. In addition, each dimension loaded on the overall PsyCap factor as follows: efficacy $=.87$, hope $=.95$, resilience $=.88$, and optimism $=.84$.

In addition to the PsyCap measure, all the other measures used in this study were also existing published instruments and revealed adequate internal reliability $(\alpha>.70)$ as seen in the diagonals of Table 1. Personality traits were conscientiousness and extraversion (the most commonly used two of the "Big Five" personality traits and, as discussed earlier, most relevant to this study). They were each measured with 10 item instruments developed by Goldberg and colleagues (2006). Each scale includes 5 positive and 5 reverse coded items. Example items from the extraversion scale are "I make friends easily" and "I keep in the background." Example items from the conscientiousness scale are "I am always prepared" and "I find it difficult to get down to work." Core self evaluation traits (CSETs) $(\alpha=.86)$ were measured using Judge and colleagues' (Judge \& Bono, 2001; Judge, Erez, Bono \& Thoresen, 2003) 12 item instrument. Items were on a scale from 1-6 ranging from Strongly Disagree to Strongly Agree. An example item is "I get the success in life I deserve."

Cynicism was measured using a 12 item instrument developed by Wanous, Reichers and Austin (2000). A sample item from this scale is "Most of the programs that are supposed to solve problems around here won't do much good." Intentions to quit were measured using 
Bluedorn's (1982) instrument which asks individuals to rate the chances that they will be employed with the organization in 3 months, 6 months, 1 year and 2 years. Ratings for the PCQ, CSET, personality and cynicism were based on a 6-point Likert scale ranging from "strongly disagree" to "strongly agree."

Counterproductive work behaviors were measured using 10 items from Fox and Spector's (1999) counterproductive work behaviors scale, which has demonstrated strong psychometric properties. Example items are "purposely ignored your boss" and "failed to help a co-worker." Ratings were on a 6-point Likert scale ranging from "Hardly, if ever" to "Frequently, if not Always". Ten items were chosen from this instrument to reduce scale length. The chosen items represented five interpersonal deviance items and five organizational deviance items. The specific items selected from each dimension were the ones with the highest reported frequency in Fox and Spector's (1999) work.

Organizational citizenship behaviors were measured with Lee and Allen's (2002) OCB instrument, which uses eight items for individual and eight items for organizational OCBs. Example items are "I go out of my way to make new employees feel welcome in the work group" and "I offer ideas to improve the functioning of the organization."

P-O and P-J fit were measured using Saks and Ashforth's (1997) instruments which include 4 items for each type of fit. Example items are "to what extent does your personality match the personality or image of the organization" (P-O fit) and "to what extent do your knowledge, skills and abilities match the requirements of your job” (P-J fit).

\section{Procedure}

On-line data collection from participants who consented on the IRB was separated into two time sessions separated by 7-14 days to help reduce common method bias (Podsakoff, MacKenzie, Lee, \& Podsakoff, 2003). First, participants on-line completed the independent, 
demographic and other control variable instruments (PsyCap, core self evaluations, extraversion, conscientiousness, person-organization fit and person-job fit). After a 7-14 day time separation, at Time 2 individuals then completed the second portion of the surveys, which included the dependant variables (cynicism, intentions to quit, OCBs and CWBs).

\section{Results}

The means, standard deviations and correlations for all study variables are presented in Table 1. Hypotheses 1 and 2 were supported as PsyCap was negatively related to cynicism $(r=-.44, \mathrm{p}<.01)$ and intentions to quit $(r=-.40, \mathrm{p}<.01)$. Hypotheses 3 and 4 were also supported as PsyCap was positively related to both individual OCBs $(r=.40, \mathrm{p}<.01)$ and organizational OCBs $(r=.58, \mathrm{p}<.01)$ and PsyCap was negatively related to CWBs $(r=-.50, \mathrm{p}<$ $.01)$.

\section{--Insert Tables 1 and 2 here--}

Multivariate tests were conducted using regression analyses. In Step 1 of the regression model, the control variables of age, gender, tenure, annual salary, job level and level of education as well as extraversion, conscientiousness, core self evaluations, P-O fit and P-J fit were entered. Next, in Step 2, PsyCap was added to determine the extent to which PsyCap predicted variance in the dependent variables above and beyond that of the control variables. As shown in Table 2, PsyCap added significant unique variance to each of the dependent variables of cynicism $\left(\Delta \mathrm{R}^{2}=\right.$ $.05, p<.05)$, intentions to quit $\left(\Delta \mathrm{R}^{2}=.02, p<.05\right)$, organizational OCBs $\left(\Delta \mathrm{R}^{2}=.02, p<.05\right)$, and CWBs $\left(\Delta \mathrm{R}^{2}=.03, p<.05\right)$. However, PsyCap did not add significant variance to the outcome of individual OCBs, the variance in which was mostly accounted for by extraversion and PJ fit. Thus, in addition to being related to the dependent variables in the hypothesized direction, PsyCap also predicted unique variance in all the outcomes except individual OCBs 
beyond the demographics, core self evaluations, extraversion, conscientiousness, P-O fit and P-J fit.

\section{Discussion}

The purpose of this study was to test the relationships of the newly emerging positive core construct of psychological capital within an overarching theoretical framework. This framework incorporates a balance of positive (e.g., organizational citizenship) and negative (e.g., cynicism, intentions to quit and counter-productive) attitudes and behavior, takes into consideration contextual factors and individual difference antecedents, and integrates a broader range of outcomes within a holistic perspective that would be relevant for the study of positivity. The results generally support the hypothesized relationships. Another important contribution of this study was that psychological capital was also shown to add variance over and above several widely recognized positive personality and self-evaluation traits, as well as person-organization and person-job fit.

Obviously there are a host of other contextual factors and individual differences, as well as other work-related outcomes, that need to be examined in future research to provide still better understanding of the unique contribution of PsyCap. However, this study contributes support to the relationship of PsyCap to yet to be tested both desirable and undesirable employee behaviors and attitudes and the added value of PsyCap over and above established trait-like positive constructs in organizational behavior in predicting these behaviors and attitudes.

The study results also provide several specific implications for both research and practice. First, PsyCap was negatively related to organizational cynicism. Thus, it is possible that those higher in PsyCap will be more supportive of organizational change, more flexible in the change process, and adapt to change better than those lower in PsyCap. Given that cynicism 
regarding organizational change can stifle organizational initiatives, development of employee PsyCap emerges as a potential human resource management strategy to counteract cynicism and promote positive change in organizations (Avey et al., 2008). Future research should expand the boundaries of PsyCap by testing its development and management in settings where various types of change (e.g., evolutionary, revolutionary, structural, cultural) are underway.

Second, PsyCap was negatively related to intention to quit. Given that intention to quit has been demonstrated to predict turnover (Crossley, Bennet, Jex \& Burnfield, in press), developing PsyCap may be an effective way to at least indirectly reduce turnover. Future research can also further investigate the mechanisms through which PsyCap contributes to turnover intentions and actual turnover (e.g., main effects, partial or full mediation, interactions).

Third, PsyCap was found to be positively related to OCBs, suggesting that those higher in PsyCap are more likely to engage in highly desirable extra-role behaviors that are so beneficial to today's organizations. Results also suggest that those who are higher in PsyCap not only engage in more desirable behaviors (OCBs), but also fewer undesirable counterproductive work behaviors (CWBs).

Future research and practice can capitalize on these findings in several ways. First, the results can contribute empirically-based input into the expanded framework for the wide range of outcomes of positivity, both positive and negative. This can provide better understanding of the nature of these outcomes, i.e., whether they represent opposite ends of a single continuum or two independent continuums. The results can also contribute to better operationalization of performance. They provide insights into going beyond in-role performance that is too often narrowly defined by outdated job descriptions and measured through short-term oriented performance appraisal systems, to include significant, but often overlooked, behaviors that matter in terms of long-term organizational effectiveness. 
Before concluding, some potential limitations of the study should be noted. First, although data collection was separated over time for the independent and dependent variables to help reduce common method bias, the data were collected in a cross sectional research design. While Podsakoff and colleagues (2003) argue this time separation procedure can help minimize the potential bias, it still must be acknowledged that the potential for common method bias and bias due to social desirability in the data, which may artificially inflate correlations and regression weights, remains a potential problem when interpreting the results of this study.

Second, while this study includes a sample of antecedents, positive state-like capacities, and positive and negative outcomes that range from attitudes to intentions to behaviors as depicted in the overarching theoretical model that framed this study, there are many other relevant variables that need to be included in future research before any generalized conclusions can be drawn (see Youssef \& Luthans, 2009 for the comprehensive conceptual framework). Some examples of variables drawn from the Youssef and Luthans (2009) framework for future research include antecedents such as life experiences; positive psychological resources such as wisdom and psychological well-being and negative states such as stress and learned helplessness; attitudinal outcomes such as positive work happiness and negative disengagement; behavioral intentions such as those concerned with morality; and behavioral outcomes such as those concerned with positive ethics and actual turnover (negative).

Third, the additional variance explained by PsyCap ranged from 2 to 5 percent, which, although statistically significant for four of the five outcome variables, may still be questioned. On the other hand, applying utility analysis and other related methodologies to actual archival data as well as a PsyCap intervention in a large aerospace firm indicate that such levels of explained variance can potentially explain substantial revenues (in the millions of dollars in large, medium and even smaller firms, see Luthans, Youssef \& Avolio, 2007, pp. 217-223) and a 
very high (over 200 percent) return on investment (see Luthans, Avey et al., 2006; Luthans, Youssef \& Avolio, 2007; Youssef \& Luthans, 2007).

\section{Conclusion}

To conclude, a positive profile of participants high in PsyCap emerges from this study. On average, they tend to be less cynical and exhibit fewer counterproductive work behaviors, are good organizational citizens, and intend to remain in the organization in the foreseeable future. Importantly, this positive profile seems to go beyond the traditionally recognized positive traits of desirable employees and, since it is state-like, is open to further development and have potential performance impact. Previous research has demonstrated that PsyCap can be developed and is related to performance and now in this study is also shown to positively be related to desirable (OCBs) and negatively to undesirable (cynicism, CWBs, and intention to quit) behaviors and attitudes. Importantly, employees' PsyCap may go beyond their demographics, positive traits, person-organization fit and person-job fit. Investing in and developing and managing the psychological capital of organizational leaders and human resources may provide the competitive advantage in meeting the growing challenges facing organizations today and certainly in the future. 


\section{References}

Avey, J.B., Wernsing, T.S., \& Luthans, F. (2008). Can positive employees help positive organizational change? Journal of Applied Behavioral Science, 44, 48-70.

Bakker, A.B., \& Schaufeli, W.B. (2008). Positive organizational behavior: Engaged employees in flourishing organizations. Journal of Organizational Behavior, 29, 147-154.

Bandura, A. (1997). Self-efficacy: The exercise of control. New York, Freeman.

Barrick, M.R., \& Mount, M.K. (1991). The big five personality dimensions and job performance: A meta-analysis. Personnel Psychology, 44(1), 1-26.

Bennett, R. J. \& Robinson, S. L. (2000). Development of a measure of workplace deviance. Journal of Applied Psychology, 85, 349-360.

Berry, C.M., Ones, D.S., \& Sackett, P.R. (2007). Interpersonal deviance, organizational deviance, and their common correlates: A review and meta-analysis. Journal of Applied Psychology, 92, 410-424.

Bluedorn, A. C. (1982). A unified model of turnover from organizations. Human Relations, 35, $135-153$.

Bryant, F.B., \& Cvengros, J.A. (2004). Distinguishing hope and optimism. Journal of Social and Clinical Psychology, 23, 273-302.

Caldwell, D.F., \& O'Reilly, C.A. (1990). Measuring person-job fit with a profile-comparison process. Journal of Applied Psychology, 75, 648-657.

Carifio, J., \& Rhodes, L. (2002). Construct validities and the empirical relationships between optimism, hope, self-efficacy, and locus of control. Work, 19, 125-136.

Carver, C., \& Scheier, M. (2002). Optimism. In C.R. Snyder \& S. Lopez (Eds.), Handbook of positive psychology, 231-243. Oxford, UK: Oxford University Press. 
Chatman, J.A. (1989). Improving interactional organizational research: a model of personorganization fit. Academy of Management Review, 14, 333-349.

Conley, J.J. (1984). The hierarchy of consistency: A review and model of longitudinal findings on adult individual differences in intelligence, personality, and self-opinion. Personality and Individual Differences, 5, 11-25.

Crossley, C. R., Bennet, R. J., Jex, S. M., \& Burnfield, J. L. (in press). Development of a global measure of job embeddedness and integration into a traditional model of voluntary turnover. Journal of Applied Psychology.

Fox, S. \& Spector, P. E. (1999). A model of work frustration-aggression. Journal of Organizational Behavior, 20, 915-931.

Fredrickson, B. (2003). The value of positive emotions. American Scientist, 91, 330-335.

Goldberg, L. R., Johnson, J. A., Eber, H. W., Hogan, R., Ashton, M. C., Cloninger, C. R., \& Gough, H. C. (2006). The International Personality Item Pool and the future of publicdomain personality measures. Journal of Research in Personality, 40, 84-96.

Hackman, J.R. (2009). The perils of positivity. Journal of Organizational Behavior, in press.

Hannah, S., \& Luthans, F. (2008). A cognitive affective processing explanation of positive leadership: Toward theoretical understanding of the role of psychological capital. In R.H. Humphrey (Ed.), Affect and emotion: New directions in management theory and research, Volume 7 of Research in Management. Greenwich, CT: Information Age.

Harter, J., Schmidt, F., \& Hayes, T. (2002). Business-unit-level relationship between employee satisfaction, employee engagement, and business outcomes: A meta-analysis. Journal of Applied Psychology, 87, 268-279.

Hobfoll, S. (2002). Social and psychological resources and adaptation. Review of General Psychology, 6, 307-324. 
Hu, L., \& Bentler, P.M. (1999). Cutoff criteria for fit indices in covariance structure analysis: Conventional criteria versus new alternatives. Structural Equation Modeling, 61, 1-55.

Jones, T. (1991). Ethical decision-making by individuals in organizations: An issue-contingent model. Academy of Management Review, 16, 363-375.

Judge, T.A., \& Bono, J.E. (2001). Relationship of core self-evaluation traits - self-esteem, generalized self efficacy, locus of control, and emotional stability - with job-satisfaction and performance: A meta-analysis. Journal of Applied Psychology, 86, 80-92.

Judge, T.A., Scott, B.A., \& Ilies, R. (2006). Hostility, job attitudes, and workplace deviance: Test of a multilevel model. Journal of Applied Psychology, 91, 126-138.

Kristof, A.L. (1996). Person-organization fit: An integrative review of its conceptualizations, measurement, and implications. Personnel Psychology, 49, 1-49.

Kristof-Brown, A. L., Zimmerman, R. D., \& Johnson, E. C. (2005). Consequences of individual's fit at work: A meta-analysis of person-job, person-organization, persongroup and person-supervisor fit. Personnel Psychology, 58, 281-342.

Law, K.S., Wong, C., \& Mobley, W.H. (1998). Toward a taxonomy of multidimensional constructs. Academy of Management Review, 23, 741-755.

Lazarus, R.S. (2003). Does the positive psychology movement have legs? Psychological Inquiry, 14, 93-109.

Lee, K. \& Allen, N. J. (2002). Organizational citizenship behavior and workplace deviance: The role of affect and cognitions. Journal of Applied Psychology, 87, 131-142.

Luthans, F. (2002a). The need for and meaning of positive organizational behavior. Journal of Organizational Behavior, 23, 695-706.

Luthans, F. (2002b). Positive organizational behavior: Developing and managing psychological strengths. Academy of Management Executive, 16, 57-72. 
Luthans, F., Avey, J.B., Avolio, B.J., Norman, S.M. \& Combs, G. M. (2006).

Psychological capital development: Toward a micro-intervention. Journal of Organizational Behavior, 27, 387-393.

Luthans, F., Avey, J.B., \& Patera, J.L. (2008). Experimental analysis of a web-based training intervention to develop positive psychological capital. Academy of Management Learning and Education, 7, 209-221.

Luthans, F., \& Avolio, B.J. (2003). Authentic leadership development. In K.S. Cameron, J.E. Dutton \& R.E. Quinn (Eds.). Positive organizational scholarship (pp. 241-258). San Francisco: Berrett-Koehler.

Luthans, F., \& Avolio, B.J. (2009). The point of positive organizational behavior. Journal of Organizational Behavior, in press.

Luthans, F., Avolio, B.J., Avey, J.B \& Norman, S.M. (2007). Psychological capital: Measurement and relationship with performance and satisfaction. Personnel Psychology, $60,541-572$.

Luthans, F., Avolio, B., Walumbwa, F., \& Li, W. (2005). The psychological capital of Chinese workers: Exploring the relationship with performance. Management and Organization Review, 1, 247-269.

Luthans, F. \& Youssef, C.M. (2007). Emerging positive organizational behavior, Journal of Management, 33, 321-349

Luthans, F., Youssef, C.M., \& Avolio, B.J. (2007). Psychological capital: Developing the human competitive edge. Oxford, UK: Oxford University Press.

Magaletta, P.R., \& Oliver, J.M. (1999). The hope construct, will, and ways: Their relations with efficacy, optimism, and general well-being. Journal of Clinical Psychology, 55, 539-551. 
Masten, A. S., \& Reed, M.G. J. (2002). Resilience in development. In C. R. E. L. Snyder, Shane J. (Ed) (Ed.), Handbook of positive psychology (pp. 74-88). London: Oxford University Press.

Mobley, W. H., Griffeth, R. W., Hand, H. H., \& Meglino, B. M. (1979). Review and conceptual analysis of the employee turnover process. Psychological Bulletin, 86, 493-522.

Parker, S. (1998). Enhancing role-breath self efficacy: The roles of job enrichment and other organizational interventions. Journal of Applied Psychology,83, 835-852.

Peterson, C., \& Chang, E. (2002). Optimism and flourishing. In C. Keyes \& J. Haidt (Eds.), Flourishing: Positive psychology and the life well-lived (pp. 55-79). Washington, DC: American Psychological Association.

Podsakoff, P. M., MacKenzie, S. C., Lee, J., \& Podsakoff, N. P. (2003). Common method biases in behavioral research: A critical review of the literature and recommended remedies. Journal of Applied Psychology, 88, 879-903.

Robinson, S. L., \& Bennett, R. J. (1995). A typology of deviant workplace behaviors: A multidimensional scaling study. Academy of Management Journal, 38, 555-572.

Sackett, P.R., Berry, C.M., Wiemann, S.A., \& Laczo, R.M. (2006). Citizenship and counterproductive behavior: Clarifying relations between the two domains. Human Performance, 19, 441-464.

Saks, A.M., \& Ashforth, B.E. (1997). A longitudinal investigation of the relationships between job information sources, applicant perceptions of fit, and work outcomes. Personnel Psychology, 50, 395

Scheier, M.F., \& Carver, C. S. (1985). Optimism, coping, and health: Assessment and implications of generalized outcome expectancies. Health Psychology, 4, 219-247.

Seligman, M.E.P. (1998). Learned optimism. New York, NY: Pocket Books. 
Seligman, M.E.P. \& Csikszentmihalyi, M. (2000). Positive psychology. American Psychologist, 55, 5-14.

Snyder, C.R. (1994). Hope and optimism. Encyclopedia of human behavior, Vol. 2, 535-542. San Diego, CA: Academic Press.

Snyder, C. R. (2002). Hope theory: Rainbows in the mind. Psychological Inquiry, 13(4), 249276.

Snyder, C. R., Harris, C., Anderson, J. R., Holleran, S. A., Irving, L. M., Sigmon, S. T., Yoshinobu, L., Gibb, J., Langelle, C., \& Harney, P. (1991). The will and the ways: Development and validation of an individual-differences measure of hope. Journal of Personality and Social Psychology, 60, 570-585.

Snyder, C. R., Ilardi, S., Michael, S. T., \& Cheavens, J. (2000). Hope theory: Updating a common process for psychological change. In C. R. Snyder, \& R. E. Ingram (Eds.), Handbook of psychological change: Psychotherapy processes and practices for the 21st century (pp. 128-153). New York: John Wiley \& Sons.

Snyder, C. R., Irving, L., \& Anderson, J. (1991). Hope and health: Measuring the will and the ways. In C. R. Snyder \& D. R. Forsyth (Eds.), Handbook of social and clinical psychology: The health perspective (pp. 285-305). Elmsford, NY: Pergamon.

Snyder, C. R., Sympson, S., Ybasco, F., Borders, T., Babyak, M., \& Higgins, R. (1996). Development and validation of the state hope scale. Journal of Personality and Social Psychology, 70, 321-335.

Stajkovic, A.D. (2006). Development of a core confidence-higher order construct. Journal of Applied Psychology, 91, 1208-1224.

Stajkovic, A., \& Luthans, F. (1998a). Self-efficacy and work-related performance: A meta-analysis. Psychology Bulletin, 44, 580-590. 
Stajkovic, A., \& Luthans, F. (1998b). Social cognitive theory and self-efficacy. Organizational Dynamics, 26, 62-74.

Wagnild, G. M., \& Young, H. M. (1993). Development and psychometric evaluation of the resiliency scale. Journal of Nursing Management, 1, 165-178.

Wanous, J. P., Reichers, A. E. \& Autsin, J. T. (2000). Cynicism about organizational change: Measurement, antecedents, and correlates. Group \& Organization Management, 25(2), 132-153.

Wright, T.A. (1997). Time revisited in organizational behavior. Journal of Organizational Behavior, 18, 201-204.

Wright, T.A. (2003). Positive organizational behavior: An idea whose time has truly come. Journal of Organizational Behavior, 24, 437-442.

Wright, T.A., \& Bonett, D.G. (2007). Job satisfaction and psychological well-being as nonadditive predictors of workplace turnover. Journal of Management, 33, 141-160.

Wright, T.A., Cropanzano, R., \& Bonett, D.G. (2007). The moderating role of employee positive well-being on the relation between job satisfaction and job performance. Journal of Occupational Health Psychology, 12, 93-104.

Wright, T.A., \& Goodstein, J. (2007). Character is not 'dead' in management research: A review of individual character and organizational-level virtue. Journal of Management, 33, 928958.

Wright, T.A., \& Huang, C.C. (2008). Character in organizational research: Past directions and future prospects. Journal of Organizational Behavior, 29, 981-987.

Wright, T.A., \& Quick, J.C. (2009). The emerging positive agenda in organizations: Greater than a trickle, but not yet a deluge. Journal of Organizational Behavior, in press. 
Youssef, C.M., \& Luthans, F. (2007). Positive organizational behavior in the workplace: The impact of hope, optimism, and resilience. Journal of Management, 33, 774-800.

Youssef, C.M., \& Luthans, F. (2008). Leveraging psychological capital in virtuous organizations: Why and how. In C. Manz, K. Cameron, K. Manz, \& R. Marx (Eds.), The virtuous organization (pp. 131-162). Hackensack, NJ: World Scientific Publishers.

Youssef, C.M., \& Luthans, F. (2009). An integrated model of psychological capital in the workplace. In A. Linley (Ed.), Handbook of positive psychology and work. New York: Oxford University Press.

Zimmerman, R.D. (2008). Understanding the impact of personality traits on individuals' turnover decisions: A meta-analytic path model. Personnel Psychology, 61, 309-348. 
Table 1

Means, Standard Deviations and Correlations

\begin{tabular}{|c|c|c|c|c|c|c|c|c|c|c|c|c|c|}
\hline & Means & S.D. & 1. & 2. & 3. & 4. & 5. & 6. & 7. & 8. & 9. & 10. & 11. \\
\hline 1. PsyCap & 4.63 & 0.67 & $(.95)$ & & & & & & & & & & \\
\hline 2. Self Evaluations & 4.49 & 0.66 & .72 & $(.86)$ & & & & & & & & & \\
\hline 3. Extraversion & 4.46 & 0.84 & .59 & .60 & $(.72)$ & & & & & & & & \\
\hline 4. Conscientiousness & 4.77 & 0.77 & .54 & .56 & .35 & $(.70)$ & & & & & & & \\
\hline 5. Person-Organization Fit & 4.31 & 1.11 & .54 & .38 & .43 & .23 & $(.95)$ & & & & & & \\
\hline 6. Person-Job Fit & 4.39 & 0.94 & .52 & .42 & .37 & .27 & .86 & $(.90)$ & & & & & \\
\hline 7. Cynicism & 2.90 & 1.06 & -.44 & -.40 & -.34 & -.17 & -.41 & -.38 & $(.94)$ & & & & \\
\hline 8. Intentions to Quit & 2.67 & 1.38 & -.40 & -.38 & -.28 & -.23 & -.51 & -.57 & .51 & $(.90)$ & & & \\
\hline 9. OCB-Individual & 4.10 & 1.02 & .40 & .40 & .38 & .35 & .42 & .50 & -.29 & -.25 & $(.90)$ & & \\
\hline $\begin{array}{l}\text { 10. OCB-Organization } \\
\text { 11. Counter Productive }\end{array}$ & 4.04 & 1.18 & .58 & .47 & .51 & .35 & .64 & .58 & -.52 & -.50 & .56 & $(.94)$ & \\
\hline Work Behaviors & 1.71 & 0.71 & -.50 & -.35 & -.28 & -.38 & -.32 & -.34 & .40 & .31 & -.33 & -.31 & $(.89)$ \\
\hline
\end{tabular}

\section{$\mathrm{N}=336$}

All correlations significant at $p<.01$

Numbers in diagonal are internal reliabilities 
Table 2

Regression Analyses with PsyCap, Outcomes and Covariates

\begin{tabular}{|c|c|c|c|c|c|c|c|c|c|c|}
\hline & \multicolumn{2}{|c|}{ Cynicism } & \multicolumn{2}{|c|}{ Intentions to Quit } & \multicolumn{2}{|c|}{ OCB-Individual } & \multicolumn{2}{|c|}{ OCB-Organizational } & \multicolumn{2}{|c|}{ CWB } \\
\hline & Step 1 & Step 2 & Step 1 & Step 2 & Step 1 & Step 2 & Step 1 & Step 2 & Step 1 & Step 2 \\
\hline Age & .079 & .062 & -.055 & -.062 & -.036 & -.029 & -.067 & -.059 & -.098 & -.110 \\
\hline Gender & -.123 & -.090 & -.134 & -.121 & .116 & .104 & .084 & .067 & $-.185^{*}$ & -.160 \\
\hline Tenure & .016 & .062 & -.092 & -.073 & .116 & .098 & .126 & .102 & -.097 & -.062 \\
\hline Job Level & -.148 & -.138 & -.014 & -.010 & -.172 & -.176 & .108 & .102 & -.044 & -.037 \\
\hline Salary & .158 & $.220 *$ & -.020 & .005 & -.113 & -.138 & -.058 & -.091 & $.207^{*}$ & $.254^{*}$ \\
\hline Education & -.166 & -.168 & -.141 & -.142 & .063 & .064 & .139 & .140 & .032 & .030 \\
\hline Extraversion & .005 & .045 & $.174 *$ & $.190 *$ & .128 & .112 & .139 & .118 & -.156 & -.126 \\
\hline Conscientiousness & .007 & .049 & -.049 & -.032 & .070 & .053 & .039 & .016 & -.153 & -.122 \\
\hline $\begin{array}{l}\text { Core Self } \\
\text { Evaluations }\end{array}$ & -.202 & .007 & -.145 & -.060 & .145 & .063 & .110 & -.001 & -.213 & -.054 \\
\hline Person-Job Fit & -.082 & -.077 & $-.474 *$ & $-.472 *$ & $.542 *$ & $.540 *$ & .058 & .056 & -.170 & -.166 \\
\hline $\begin{array}{l}\text { Person-Organization } \\
\text { Fit }\end{array}$ & -.181 & -.096 & .010 & .045 & -.210 & -.243 & $.374 *$ & $.329 *$ & .005 & .069 \\
\hline PsyCap & & $-.420 *$ & & $-.170 *$ & & .165 & & $.222 *$ & & $-.318^{*}$ \\
\hline Total $\mathrm{R}^{2}$ & $.260^{*}$ & $.315^{*}$ & $.380 *$ & $.401 *$ & $.369 *$ & $.378^{*}$ & $.470 *$ & $.490 *$ & $.266^{*}$ & $.294 *$ \\
\hline$\Delta$ in $\mathrm{R}^{2}$ & & $.054^{*}$ & & $.02 *$ & & .01 & & $.02 *$ & & $.03 *$ \\
\hline
\end{tabular}

$\mathrm{N}=336$

$* \mathrm{p}<.05$ 